\title{
In depth psycho-sociological interview (intake) and placement for treatment in case of combat PTSD
}

\begin{abstract}
In this article, I will describe a method of conducting an in-depth psycho-sociological interview -"intake" - for combat PTSD victims, based on a process that has been adapted by the Unit for Treatment of Combat-Related PTSD (UTC-PTSD) of the Israel Defense Forces (IDF). This process is extremely complex, due to the need to make a decision based on a diagnosis that relies mainly on the therapist's subjective impression. This complexity is even greater for Combat PTSD victims, since this disorder is usually accompanied by additional disorders, such as depression, that complicate diagnosis. The structured process of diagnosis is based on an in-depth psych-sociological interview and questionnaires. This process is intended, among others, to implement the approach of the Mental Health Division of the IDF as formulated in the ethical code of the mental health officers, according to which "the types of treatment should be adapted to the individual's characteristics". The present article will attempt to shed light on the nature of the intake, screening and placement process that takes place in case of Combat PTSD. I will illustrate the attempt to examine the applicant's history until the traumatic event, the characteristics of the event and its circumstances, and the effects of the event on the applicant's present function. Then I will describe the decision-making process at the staff meeting, and the types of therapy implemented.
\end{abstract}

Keywords: intake, psycho-sociological interview, PTSD, combat
Volume 3 Issue 6 - 2017

\author{
Ofir Levi \\ Social Work Department, Ruppin Academic Center, Tel-Aviv \\ University, Israel
}

Correspondence: Ofir Levi, Senior Lecturer, Social Work Department, Ruppin Academic Center \& Head of the Psychodynamic Psychotherapy, Bob Shapell School of Social Work, Tel-Aviv University, Lieutenant Colonel (Retired), IDF, Israel, Tel +972 3 6409355, Email ofirleviphd@gmail.com

Received: July 15, 2017 | Published: July 27, 2017
Abbreviations: PTSD, post-traumatic stress disorder ; IDF, israel defense forces; ADS, acute distress disorder; ASR, acute stress reaction; DSM-PD, diagnostic and statistical manual of psychiatric disorders; CAPS, clinical administrated ptsd scale; MADRS, montgomery asberg depression rating scale

\section{Introduction}

The Unit for Treatment of Combat-Related PTSD (UTC-PTSD) of the Israel Defense Force (IDF) consists of a multi-professional team that includes expert psychiatrists, clinical psychologists and social workers. ${ }^{1}$ Since the First Lebanon War, the status of the UTCPTSD has become established as a therapeutic unit that specializes in psychiatric and psycho-therapeutic treatment of chronic PTSD victims, ${ }^{2}$ combat stress response victims ${ }^{3}$ and acute distress disorder (ADS) victims, as well as in preventive activity in these three fields. ${ }^{4}$ Admission for treatment in each of these cases is carried out by indepth psycho-sociological interview, a process which in professional jargon is called "intake." The intake process lasts two to three intake sessions with one therapist, with one week between sessions. Each session lasts on average about one and a half hours. The average number of intake sessions was two and a half sessions per applicant.

\section{From combat stress reaction to chronic pos- t-trauma}

"Combat stress reaction" is a transient mental reaction to a situation of unusual stress, such as combat and war, and is considered to be part of the posttraumatic stress disorder. The reaction is expressed in emotional flooding which makes it difficult to recruit the necessary strength for coping. ${ }^{3}$ The symptoms of the reaction are expressed in the behavioral-emotional field (sadness, confusion, crying), the physical field (headaches, shaking, palpitations), the cognitive field (inability to receive stimuli, difficulties in concentration), sleep disorders (nightmares), etc. The response may weaken and even disappear, or alternately it may exacerbate such that it causes significant mental, functional and behavioural impairment. ${ }^{5}$ Approximately 76 percent of those exposed to a traumatic event will develop at least one possible symptom of acute stress reaction (ASR). Most of these (about 70 percent) will recover with the support of "natural support factors" (their service mates in the division or company). ${ }^{6}$ Those who do not recover within 72 hours of the exposure to the traumatic event will be defined as suffering from acute stress disorder (ASD). If they do not recover within one month, they will be defined as suffering from PTSD. Figure 1 summarizes the development of chronic post-trauma from the first moments of exposure to the event.

The syndrome was first diagnosed in the DSM in 1980, following the activity of Vietnam War veterans. It is defined and described in the Diagnostic and Statistical Manual of Psychiatric Disorders, DSMIII (1980) and with slight modifications in DSM-III-R (1987), DSMIV (1994), in DSM-IV-TR (2000) and DSM-5 [2013].7 According to the DSM definition, PTSD appears following a traumatic event in which the person was exposed to: death, threatened death, actual or threatened serious injury, or actual or threatened sexual violence, in the following ways:

a. Direct exposure, witnessing the trauma, learning that a relative or close friend was exposed to a trauma and indirect exposure to aversive details of the trauma, usually in the course of professional duties (e.g. first responders, medics). The subjective meaning that the person attributes to the traumatic event should be emphasized during intake and assessment of its influence on the victim's function, although this should not be regarded as the sole etiological cause (Figure 2). 
PTSD will be diagnosed in a person who suffers from symptoms that belong to four clusters

Re-experienced (cluster $\mathrm{B}$ in which one out of 5 symptoms is required), avoidance (cluster $\mathrm{C}$ in which one of two symptoms is required), negative thoughts or feelings (cluster $\mathrm{D}$ in which two out of seven symptoms are required) and arousal and reactivity (cluster E in which two out of six symptoms are required) - for at least one month These symptoms can appear immediately or close to the traumatic event and sometimes after some time, after months or even years.

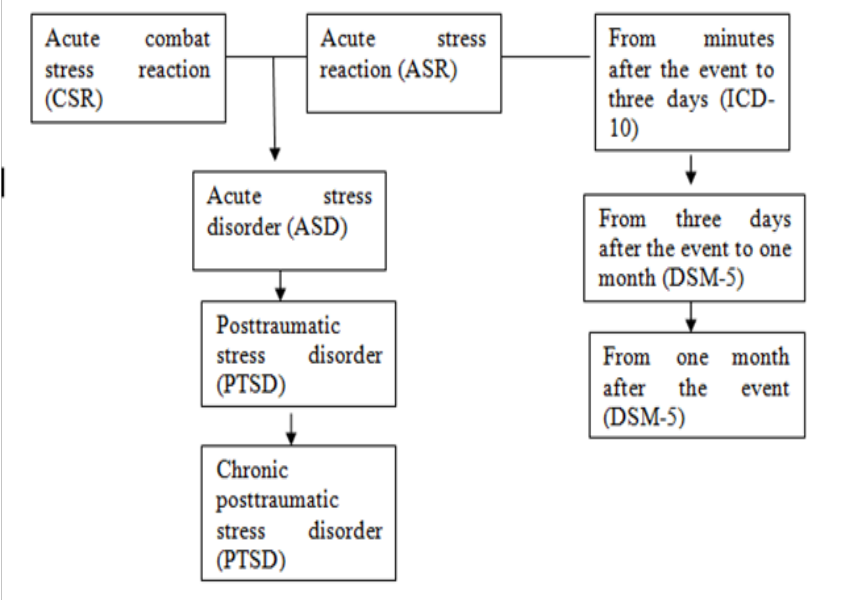

Figure I Development of chronic post-trauma.

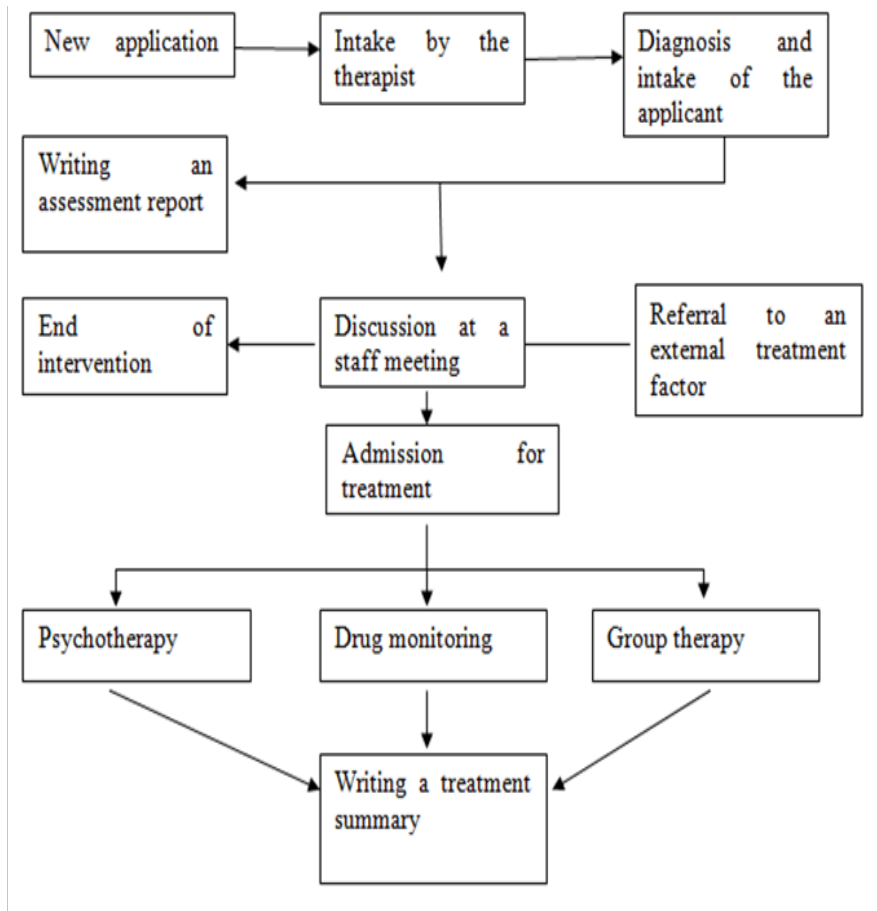

Figure 2 Intake and placement for treatment at the CSR Unit.

\section{Psycho-sociological interview (intake)}

The psycho-sociological interview (intake) is a structured interview for learning the applicant's history until the traumatic event, the characteristics of the event and its circumstances and the effects of the event on the applicant's present function. Its goal is to examine the applicant's clinical condition and reach a diagnosis. The first stage of the interview can be called "the stage of setting the atmosphere". During this stage emphasis is placed on creating an atmosphere that will enable building trust between the therapist (henceforth "the intaker") and the applicant, which will lead to the creation of a sense of confidence in the applicant. Everyone at the UTC-PTSD is therefore strict about receiving the applicant in the reception room at exactly the time that was set for him, and to lead him to the therapist's room to a pleasant and informal sitting corner. The small gestures (body language) and the things that the intaker says thus affect the intake process.

The professional and humane confidence that the intaker broadcasts is the first step towards returning the basic sense of confidence that the applicant lost following the horror of the traumatic event. ${ }^{8}$ One of the things that help create boundaries is the messages that the intaker who performs the intake passes to the applicant at the beginning of the first intake session. During this session the intaker customarily introduces himself, the Unit and the intake process, its goals and nature ("I will present questions which you will be asked to answer with the goal of understanding the nature of the problem and possible ways to help solve it"). The difference between the intake sessions and the treatment sessions is emphasized. This session gives expression to the human gesture that personifies basic human respect. The therapist explains the process to the patient as an adult person with intellectual abilities, which is compatible with Casement's recommendations ${ }^{9}$ on the correct approach to contact with patients. Furthermore, this demonstrates the therapist's willingness to help, alongside a demonstration of confidence that is embedded in the presentation of a clear and continuous framework. These create a preliminary sense of hope ${ }^{10}$ which is important for beginning the encounter with the content world of the treatment and the applicant's preparedness and desire to continue with the treatment. ${ }^{11}$

The structured psych-sociological interview is based on a series of organized and orderly questions that are compatible with the individual's life course. It begins with basic socio-demographic details that are recorded in the admission form. In the next stage, the applicant is asked to describe the symptoms from which he is suffering in the present their severity, duration and nature and their influence on his function. The intaker is strict to enable the applicant to describe the symptoms in his own words and according to his perception without intervening, in order to gain an initial impression of the severity of the distress and its nature. This initial information is formulated at the top of the intake form.

After clarification of the applicant's psychiatric development during early childhood, the therapist focuses on the nuclear family, its composition, his position among his siblings, the relations between the parents and the children and the relations between the siblings. The relations between the applicant and his parents and siblings are given special emphasis, in order to determine the emotional atmosphere in the family, its values, life norms and function level. In addition to all of these, a clarification of traumas that took place in the family is carried out, including exposure of a family member to trauma on the background of combat and the existence of major psychopathology in the family. These are intended to understand the family influences on the development of the post-traumatic symptoms after exposure to the trauma of combat for which the applicant seeks help in the present.

In the next stage, the intaker focuses on the learning level, and 
emphasizes passages between schools, leisure activities, relations with his peer group, discipline problems, use of drugs and alcohol and entanglement with the law. These shed light on persistence processes, ability to accept responsibility and authority, adjustment difficulties and personality characteristics (introversion versus extraversion, etc.) significant variables for understanding the characteristics of the trauma and its severity in the present. For example, an applicant who was characterized by difficulties in persistence and adjustment during adolescence which were expressed also in the military system will cause the intaker to doubt his ability to persist in the treatment and take responsibility for his psychological problem in the present. This question is very important in making the decision at the staff meeting that will be described henceforth. After finishing this part of the intake process, the intaker focuses on the adjustment and integration of the applicant in the military system. At this stage emphasis is placed on the professional and social integration in the military system, and above all the mental integration. The applicant is asked to describe the traumatic event which he experienced in order to understand its nature, severity, duration, level of danger to which he was exposed and the symptoms that developed following the event. In this context, the intakers of the Unit are strict to ask when the symptoms began and how long he has been suffering from them.

When the circumstances of the event and its duration are clear, the applicant is asked to describe his life history after finishing his military service. This part sheds light on the processes of choice in the field of studies, acquisition of a profession and occupational integration and the choosing of a mate and starting a family. This is the basis for examining the adjustment, persistence and function at the occupational and family level. Under the assumption that the applicant has function difficulties, he is asked to assess the trauma's contribution to his difficulties in functioning. This affords a perspective on the patient's maturity and ripeness.

The applicant's partner is also invited to the Unit in order to obtain her reference to the nature of the problem, its characteristics and severity. In addition to information on the nature of the applicant's problem, the partner affords a possible contribution to the development and nature of the trauma. This is important for the discussion on the type of treatment at the staff meeting, which may involve couple or family therapy. The last stage in the intake process, before the staff summarizes and makes its diagnosis, is the stage of filling in questionnaires. These include the CAPS (Clinical Administrated PTSD Scale), ${ }^{12}$ a questionnaire which is filled in by the applicant together with the intaker, as well as self-filling questionnaires that include the MADRS (Montgomery Asberg Depression Rating Scale) ${ }^{13}$ for testing the level of depression, the Hope Scale, ${ }^{14}$ the POAMS ${ }^{15}$ for testing everyday function and the PTSD. ${ }^{16}$ In general, these questionnaires help the intaker and the staff and do not serve as a sole and determining diagnostic tool. In other words, the intaker's clinical impression has greater weight than the results of the questionnaires in the decision-making process at the staff meeting.

In conclusion, the purpose of the psych-sociological interview is to examine and test the circumstances of the traumatic event which the applicant describes and the factors that influenced the nature and severity of the combat stress reaction. During this interview the intaker searches for risk factors for the development of chronic post-trauma, and the effects of these risk factors on the applicant's function in the present. The therapist proposes a diagnosis based on all of the above, with reference to the severity of the symptoms and their influence on the applicant's function.

\section{The decision-making process at the staff meeting}

At the staff meeting the applicant's file is presented by the therapist who carried out the intake, and this serves as the basis for making a decision pertaining to the diagnosis and the suitable treatment. When presenting the case, the intaker emphasizes the applicant's complaints, his process of development, the characteristics of the event and the nature of the symptoms that developed following the event, his diagnosis and the type of treatment which he deems appropriate - and gives his rationale for the choice. In its discussions, the staff focuses on the question of the diagnosis, the severity and the type of treatment: treatment with a psychoanalytical orientation (henceforth: "dynamic therapy"), various types of cognitive-behavioral therapy, couple, group, drug or combined therapy (drug and another type of therapy).

Referral for cognitive-behavioural therapy stems from the nature of the clinical picture. An applicant who suffered from focused symptoms that indicate concrete dysfunction, such as difficulty in entering closed places, difficulty in using public transportation, etc. will be referred to cognitive-behavioural therapy. It should be indicated that an applicant who exhibits symptoms of an acute stress response or an acute stress disorder, which occur during the first month of exposure to the event, will always be treated with a behavioural-cognitive orientation. ${ }^{1}$ As a rule, cognitive-behavioural therapy is directed to cases in which the applicant evaluates the traumatic event as so severe that he develops negative beliefs, such as: "it is not safe anywhere", "the next disaster will strike soon", "I am dead inside", or "I'm going mad", which lead to dysfunction. Because of these negative beliefs, the traumatic experience is not internalized in the applicant's autobiographic memory, thus adding to the dysfunction.

Treatment is therefore intended to identify the thinking errors at the root of the victim's negative evaluation of the traumatic event and his beliefs on dysfunction, while constructing adjustive thinking alternatives. An attempt is made to find positive meaning for the traumatic event, with the goal of assimilating the traumatic experience in the applicant's autobiographic memory. Emphasis in therapy is thus on current problems that are accessible to analysis. Another aspect that belongs to this method of treatment pertains to perception of the traumatic event as a fear response. People who are exposed to critical situations respond by biological arousal, fear and anxiety when they encounter associative reminders of the trauma. They avoid exposure to things that remind them of the trauma in order to avoid these responses, and therefore do not undergo the natural process of extinction. Foa \& Rothbaum ${ }^{17}$ understand the fear as a cognitive structure that contains representations of frightening stimuli, fear responses and the meaning connected to the stimuli and responses. Treatment should arouse the memory of the fear, and introduce new information that counteracts unsuitable elements in the existing structure.

When the applicant presents a clinical picture that is compatible with chronic post-trauma which indicates extensive dysfunctions (at the occupational, interpersonal, family and couple level) and/or evidence of developmental-personality pre-morbidity, and when he exhibits insight, symbolization and abstraction ability, he will usually be referred for dynamic therapy. This therapy method is intended to help the patient understand the effect of the traumatic event on his personality, based on his experiences since the event, concomitantly with touching upon his relations with significant figures from his past (which are sometimes reflected in the relations he creates with his therapist) and their influence on the assimilation of the event in 
the present. The meanings of the event, the personal response to the event and the behaviours that developed after the event are examined concomitantly. These are intended for the patient to develop insights as to the factors that activate him, until he achieves mastery over his internal experiences by more effective coping. ${ }^{18}$

Another therapeutic tool for the therapist is referring the victim for group therapy. ${ }^{19}$ Each year two therapy groups open at the CSR Unit, according to age: one for victims of the Six Days War, the Yom Kippur War and the First Lebanon War and one for victims of the Second Intifada and the Second Lebanon War. Suitableness for integration in the group includes an evaluation of the ability and willingness for exposure to and bearing the stories and experiences of others, and the ability to become integrated and gain from the group process for coping with difficulties outside the treatment room. This treatment is based on the assumption that the peer group is very constructive for coping with the outcomes of exposure to a traumatic event. Another assumption is that the peer group affords the individual relief from the social loneliness that is characteristic of people who suffer from chronic post-trauma. Group therapy at the CSR Unit is usually "psycho-dynamic-supportive" therapy, since it combines elements of discussion of the main conflicts that are prominent among most of the patients, the ways in which they cope, their defence mechanisms, their object relations, and parts of interpersonal learning through cognitivebehavioural and supportive expressions.

Referral for drug therapy is made in cases of complaints of prolonged post-trauma in which symptoms of sleep difficulties, increased anxiety, sadness or a combination of these are prominent. In some of the cases the applicants have been suffering from the syndrome for many years. However, applicants who were exposed to the traumatic experience in the shorter term may also be treated with drugs, if the severity of the symptoms causes significant difficulties in concentration, unceasing thoughts about the event, sleep difficulties and loss of control "up to madness". ${ }^{4}$

Drug therapy focuses on accompanying symptoms (depression, anxiety, sleeping difficulties) to the disorder, in the absence of drug treatment for the disorder. There are positive reports on alleviation of depression, anxiety and sleep disorders in this context. ${ }^{20}$ Supportive conversations are integrated within the framework of this treatment, whose purpose is to afford the patient emotional support, by touching on the emotional difficulties that accompany him and their effect on his function. In these conversations, the therapist is strict not to reflect or interpret things that the patient does not mention of his own accord, and integrates elements of guidance (psycho-educational elements). Referral for couple or family therapy will be made in cases of prominent dysfunction on the couple-family level (which is usually reinforced in the interview with the partner), and in the extent of the partner's motivation to cooperate with such therapy. It should be indicated that many of the female partners prefer that their partner be treated separately, and assume that he is the one with the main problem. $^{3}$

\section{Conclusion}

In this article, I tried to describe the intake process that takes place at the CSR Unit, a process that has been formulated into its current design during the past five years. The description of the intake process and the manner in which the professional decisions are made at the Unit as to the choice of treatment for the applicant may help other professionals who work in treating different groups of post-trauma victims on a background of different traumatic events. Needless to say, these decisions must be tested in a clinical research that will evaluate the effectiveness of the therapy methods employed at the CSR Unit, a research which we are currently carrying out.

\section{Acknowledgements}

None.

\section{Conflict of interest}

The author declares no conflict of interest.

\section{References}

1. Levi O, Bar-Haim Y, Kreiss Y, et al. Cognitive Behavioural Therapy and Psychodynamic Psychotherapy in the Treatment of Combat-Related Post-Traumatic Stress Disorder: A Comparative Effectiveness Study. Clin Psychol Psychother. 2016;23(4):298-307.

2. Levi O, F Fruchter, Y Kreiss. From captivity to freedom: A challenge for the released prisoner and for the therapist. Journal of Israeli Military Medicine. 2013;10(2):12-19.

3. Solomon Z. Combat stress reaction: The enduring toll of war. New York: Plenum Press; 1993.

4. Levi O, et al. The Efficacy of the cognitive-behavioral treatment, dynamic treatment, group treatment and drug therapy among chronic PTSD patients at the unit for the treatment of combat stress reaction: findings based on therapists' experiences. Journal of Military Medicine. 2012;9(1):5-11.

5. Shalev AY, Tuval R, Frenkiel-Fishman S, et al. Psychological responses to continuous terror: a study of two communities in Israel. Am J Psychiatry. 2006;163(4):667-673.

6. Bleich A, Gelkopf M, Solomon Z. Exposure to terrorism stress-related mental health symptoms and coping behaviors among a nationally representative sample in Israel. JAMA. 2003;290(5):612-620.

7. Diagnostic and statistical manual of psychiatric disorders DSM-5 ${ }^{T M}$. 5th ed. Washington, USA: APA; 2013. 991 p.

8. Herman LJ. Trauma and recovery. Sifriyat Ofakim Am Oved, Israel. 1992.

9. Casement P. Unconscious hope. In: P Casement, Further learning from the patient. Dvir Tel-Aviv, Israel. 1995.

10. Levi O. Hope phenomenon in the treatment of Post Traumatic Stress Disorder. Sihot-Dialogue Israel Jouranal of Psychotherapy. 2008;233245 .

11. Snyder CR. Handbook of hope: Theory measures and applications. California: Academic Press; 2000. 440 p.

12. Blake DD, Weathers FW, Nagy LM, et al. The Development of a Clinician-Administered PTSD Scale. J Trauma Stress. 1995;8(1):75-90.

13. Montgomery SA, Asberg M. A new depression scale designed to be sensitive to change. Br J Psychiatry. 1979;134:382-389.

14. Snyder CR, Harris C, Anderson JR, et al. The will and the ways: development and validation of an individual-differences measure of hope. $J$ Pers Soc Psychol. 1991;60(4):570-585.

15. Green JL, JL Lowry, SM Kopta. College students versus counselling center clients: What are the differences? Journal of College Student Psychotherapy. 2003;17(4):25-37.

16. Solomon Z, Benbenishty R, Neria Y, et al. Assessment of PTSD: validation of the revised PTSD Inventory. Isr J Psychiatry Relat Sci. 1993;30(2):110-115. 
17. Foa EB, Rothbaum BO (1998) Treating the trauma of rape Cognitive behavioral therapy for PTSD. New York: Guilford Pres; 1998. p. 1-7.

18. Kudler H. Treating PTSD in military personnel a clinical hand book. In: BA Moore, WE Penk, editors. New York: The Guildford Press; 2011. 382 p.

19. Levi O, Shoval-Zuckerman Y, Fruchter E, et al. Benefits of a Psychodynamic Group Therapy (PGT) Model for Treating Veterans with PTSD. J Clin Psychol. 2017.
20. Shalev AY, Videlock EJ, Peleg T, et al. Stress hormones and post-traumatic stress disorder in civilian trauma victims: a longitudinal study. Part I: HPA axis responses. Int $J$ Neuropsychopharmacol. 2008;11(3):365-372. 